\title{
Green Synthesis of Silver Nanoparticles Using Hydnocarpus pentandra Leaf Extract: In-vitro Cyto-Toxicity Studies Against MCF-7 Cell Line
}

\author{
Krishna kumar K', Dinesh kumar B' ${ }^{2}$, Rini Ramesh Punathil ${ }^{2}$ \\ 'Department of Pharmaceutics, St James College of Pharmaceutical Sciences, Chalakudy, Kerala, INDIA \\ ${ }^{2}$ St James Hospital Trust Pharmaceutical Research Centre (DSIR Recognized), Chalakudy, Kerala, INDIA
}

\begin{abstract}
Objective: To synthesize silver nanoparticles from leaves extract of Hydnocarpus Pentandra ( $H$. Pentandra) and test the anti-cancer activity of synthesized silver nanoparticles against breast cancer cell line (MCF-7 cells). Method: Ten milliliter of leaves extract was mixed with $10 \mathrm{~mL}$ of aqueous $1 \mathrm{mM}$ silver nitrate solution and kept in an incubator shaker system at $37^{\circ} \mathrm{C}$ for 24 hours. During this period, yellowish to reddish-brown color changes was observed. Characterization of silver nanoparticles using UV-vis spectrophotometry and SEM analysis were performed. Antioxidant activity of silver nanoparticles was performed using DPPH method. Anti-cancer activity of silver nanoparticles was tested using in vitro cytotoxicity test with 3-(4,5-Dimethylthiazol-2-yl)-2,5-diphenyltetrazolium bromide against MCF-7 breast cancer cells. Results: UV-vis spectral analysis indicated the sliver surface plasmon resonance band at $438 \mathrm{~nm}$. SEM analysis showed that silver nanoparticles to be spherical in shape with a size in the range of $141 \mathrm{~nm}$ to $202 \mathrm{~nm}$. The synthesized silver nanoparticles exhibited antioxidant activity at dose dependent manner using DPPH method. The synthesized
\end{abstract}

silver nanoparticles efficiently reduced the viability of MCF-7 breast cancer cells in a dose dependent manner. Conclusion: It has been demonstrated that the leaves extract of Hydnocarpus Pentandra could produce silver nanoparticles and the silver nanoparticles are quite stable in solution. Further studies are needed to characterize the mechanism involved with anti-cancer activity of the silver nanoparticles.

Key words: Hydnocarpus Pentandra, Leaf, Anti-Oxidant, Anti-Cancer Activity. Correspondence

Dr. K. Krishnakumar, St James College of Pharmaceutical Sciences, Chalakudy, Kerala, INDIA.

Phone: 04802710936

Email: stjamespharmacyproject@gmail.com

DOI: $10.5530 /$ jyp.2018.10.5

\section{INTRODUCTION}

The development of green synthesis of silver nanoparticles is evolving in the field of nanotechnology. The research on silver nanoparticles is an emerging field of pharmaceutical sciences due to its huge applications. The known application of silver and silver nanoparticles including topical ointments, creams containing silver has been used for the treatment of burn wounds. Many methods has been reported for synthesis of silver nanoparticles such as reduction in solutions, chemical and photochemical reductions in reverse micelles, thermal decomposition of silver, electrochemical, sonochemical, radiation assisted and microwave assisted methods. Recently, biological methods has been reported for synthesis of silver nanoparticles such as silver nanoparticles synthesis using microorganism, enzymes and plant extracts. The biological methods is environmentally friendly, cost effective, suitable for large scale production and this method offers numerous benefits over chemical and physical methods such as there is no need of high energy, high pressure, temperature and no use of chemicals. ${ }^{1,2}$ Among various known synthesis methods, plant extract mediated silver nanoparticle synthesis is widely preferred as its cost-effective, environmentally friendly and safe for human therapeutic uses. ${ }^{3}$ Some research studies has been reported to use silver nanoparticles as an anti-cancer agents. The role of silver nanoparticles as an anti-cancer agent could open a new doors in the field of pharmaceutical as well as medical sciences. ${ }^{4}$

Green-synthesized silver nanoparticles (AgNPs) from methanolic extracts of Vitex negundo L. (at a concentration $20 \mu \mathrm{g} / \mathrm{mL}$ ) showed 50\% inhibition of the cell viability of human colon cancer cell lines (HCT 15). ${ }^{5}$ Synthesized AgNPs from whole plant of Acalypha indica showed cytotoxic properties against MDA-MB-231 cells (human breast tumor cells) ${ }^{6}$ Synthesis of AgNPs from Andrographis echioides leaves (at a concentration $31.5 \mu \mathrm{g} / \mathrm{mL}$ ) inhibited the growth of MCF-7 cells (human breast adenocarcinoma cell line)?

In the present study, we report for the first time synthesis of silver nanoparticles, reducing the silver ions of silver nitrate by the aqueous extract of Hydnocarpus Pentandra leaves. Morphological characterizations are performed using SEM analysis. The optical absorption spectrum of silver nanoparticles was recorded using UV-Vis spectrophotometer. Antioxidant activity of synthesized AgNPs were performed using DPPH method and also silver nanoparticle toxicity efficacy against MCF-7 breast cancer cell line were evaluated.

\section{MATERIALS AND METHODS}

\section{Materials}

Fresh leaves of Hydnocarpus Pentandra were identified and collected from Chalakudy, Thrissur, and authenticated by Dr. Jalaja S Menon, Kerala Agricultural University, Thrissur, Kerala. The voucher specimen was numbered (KAU/05/HP/SJCOPS/2015) and kept in our research laboratory for the reference. Silver nitrate was obtained from the Nice Chemicals Ltd, Ernakulum, and Kerala. 


\section{Synthesis of silver nanoparticles}

The fresh leaf of Hydnocarpus Pentandra solution was prepared by taking $10 \mathrm{~g}$ of washed and finely cut leaves in $300 \mathrm{~mL}$ Erlenmeyer flask along with $100 \mathrm{~mL}$ of sterilized distilled water and boiled the mixture for $5 \mathrm{~min}$ before finally decanting it. The extract was filtered through Whatman filter paper no 1 and stored under refrigeration condition. The filtrate was treated with $1 \mathrm{mM}$ silver nitrate solution in an Erlenmeyer flask and incubated at room temperature. As a results, a brown-yellow colour changes occurred in the solution due to formation of silver nanoparticles. It indicated that aqueous silver ions could be reduced by aqueous extract of $H$. Pentandra to produce stable silver nanoparticles in water.

\section{Characterization of synthesized silver nanoparticles}

Synthesis of silver nanoparticles solution with leaves extract of $H$. Pentandra was observed by UV-Vis Spectroscopy. The bio-reduction of precursor silver ions in the solutions was monitored by sampling of aliquots $(1 \mathrm{~mL})$ of aqueous component and measured the UV-Vis spectra of the solution. Shimadzu UV-Vis spectrophotometer in $200 \mathrm{~nm}$ to $600 \mathrm{~nm}$ range was operated at a resolution of $1 \mathrm{~nm}$.

\section{Scanning Electron Microscope (SEM) Analysis}

SEM is a type of electron microscope that images a sample by scanning it with a high-energy beam of electrons in a raster scan patterns. Synthesized silver nanoparticles were subjected to Scanning Electron Microscope (JEOL model JSM-6390 LV) analysis. Thin films of the sample was prepared on the copper grid by dropping a small quantity of sample on the grid and then the films on the grid was allowed to dry under mercury lamp for 5 mind. Then it was fixed in to sample holder and placed in a vacuum chamber of the scanning electron microscope and observed under low vacuum and SEM images were recorded.

\section{In-vitro anti-oxidant activity}

The antioxidant activity was determined using the 2, 2-diphenyl-1-picryl hydrazyl (DPPH) free radical scavenging method. The free radical scavenging ability of synthesized silver nanoparticles against DPPH free radical was evaluated. $1 \mathrm{ml}$ of $0.1 \mathrm{mM}$ DPPH in ethanol was prepared. To that prepared solution synthesized silver nanoparticles varying in concentrations $(25 \mu \mathrm{g} / \mathrm{ml}, 50 \mu \mathrm{g} / \mathrm{ml}$ and $100 \mu \mathrm{g} / \mathrm{ml}), 1 \mathrm{ml}$ ethanol and $0.95 \mathrm{ml}$ Tris $\mathrm{HCl}$ were added. The mixture was left for 30 minutes and the absorbance was measured at $517 \mathrm{~nm}$. Ascorbic acid was used as standard drug. The DPPH free radical scavenging activity was subsequently calculated using following formula:

$$
\% \text { DPPH radical scavenging }=\frac{\text { Control OD }- \text { Sample OD }}{\text { Control OD }} \times 100
$$

MTT assay for screening of anti-cancer activity: The 3-(4,5-dimethylthiazol-2-yl)-2,5- diphenyl tetrazolium bromide) dye reduction assay was conducted to diagnose the cytotoxicity study of the synthesized silver nanoparticles. MCF-7 cells were plated onto 48 wells plates, 18 hours before the commencement of the test. Growth medium used was DMEM with $10 \%$ Fetal Bovine Serum. The plates were incubated in an animal cell culture incubator, maintained at $37^{\circ} \mathrm{C}$ with $5 \%$ carbon dioxide. The wells achieved $70 \%$ confluency at the time of testing. The original growth medium in the 48 well plates was removed and the sample (synthesized silver nanoparticles with varying in concentrations $(25 \mu \mathrm{g} / \mathrm{ml}, 50 \mu \mathrm{g} / \mathrm{ml}$ and $100 \mu \mathrm{g} / \mathrm{ml}$ ) were added to the wells. The plates were returned to the incubator for 24 hours. At the end of 24 hours, the media in the wells were carefully removed and fresh complete growth media was added. To each well, MTT solution ( $5 \mathrm{mg} / \mathrm{ml}$ of MTT dissolved in PBS) was added and replaced in the incubator for 3 hours. After 3 hours, the medium was carefully removed from the wells, and DMSO was added to each well and kept on a rocking platform for efficient mixing and extraction of formazan dye from the cells by DMSO. After 30 minutes, the absorbance of the DMSO was measured at $570 \mathrm{~nm}$, in a multi-well spectrophotometer. The average absorbance of the "control" wells was taken as $100 \%$ and all other absorbance values were calculated based on this and plotted on the graph. The percent viability of cells was calculated by using the following formula.

$$
\text { Percentage Viability }=\frac{\text { OD of Test }}{\text { OD of Control }} \times 100
$$

A graph was plotted against the \% viability Vs dilution of the sample. The results were given as the mean \pm SD of three independent experiments.

\section{Statistical Analysis}

The experiments were carried out in triplicates analysis of the data were performed by excel sheet. The results were expressed as mean \pm standard error.

\section{RESULTS}

Green synthesis of silver nanoparticles using $1 \mathrm{mM}$ silver nitrate was shown in Figure 1. The fresh solution of $H$. pentandra leaves was yellowish in colour. However, after addition of silver nitrate and exposing to room temperature for $24 \mathrm{~h}$, the solution turned to reddish brown due to formation of silver nanoparticles.

\section{UV-Vis spectra analysis}

Formation of synthesized silver nanoparticles was confirmed by using UV-Visible spectral analysis and indicated that silver surface plasmon resonance band at $438 \mathrm{~nm}$ (Figure 2).

\section{SEM Analysis}

SEM studies was employed to visualize the size and shape of silver nanoparticles. In Figure 3, SEM images were obtained with 10\% of Hydnocarpus pentandra leaves solution. The SEM (JEOL model JSM-6390 LV) used SEM grids which were prepared by placing a small quantity of sample powder on a copper coated grid and drying under mercury lamp. The silver nanoparticles and their morphological dimensions in the SEM analysis indicated that the average size was from $141 \mathrm{~nm}$ to $202 \mathrm{~nm}$ with inter-particle distance. The shapes of synthesized silver nanoparticles were confirmed to be spherical (Figure 3).

\section{Anti-oxidant activity by DPPH method}

1,1-diphenyl-2-picryl hydrazyl (DPPH) is stable free radical which get reduced by accepting hydrogen or electron from donor. Synthesized silver nanoparticles with varying in concentrations $(25 \mu \mathrm{g} / \mathrm{ml}, 50 \mu \mathrm{g} / \mathrm{ml}$ and $100 \mu \mathrm{g} / \mathrm{ml}$ ) indicated remarkable scavenging activity when compared with standard ascorbic acid. DPPH scavenging activity of synthesized silver nanoparticles was found to have anti-oxidant activity in a dose dependent manner. The antioxidant potential of silver nanoparticles may be presence of functional groups adhere to nanoparticles from leaf extract (Figure 4).

The in-vitro cytotoxic effects of silver nanoparticles were performed against MCF-7 breast cancer cell line and viability of tumor cells was confirmed using MTT assay. The silver nanoparticles were able to reduce viability of the MCF-7 cells in a dose-dependent manner. After $24 \mathrm{~h}$ treatment, the silver nanoparticles at a concentration $25 \mu \mathrm{g} / \mathrm{ml}, 50 \mu \mathrm{g} / \mathrm{ml}$ and $100 \mu \mathrm{g} / \mathrm{ml}$ showed toxicity to MCF-7 breast cancer cells in a dose dependent manner and reached to $87 \%$ of dead cells after $24 \mathrm{~h}$ incubation. 

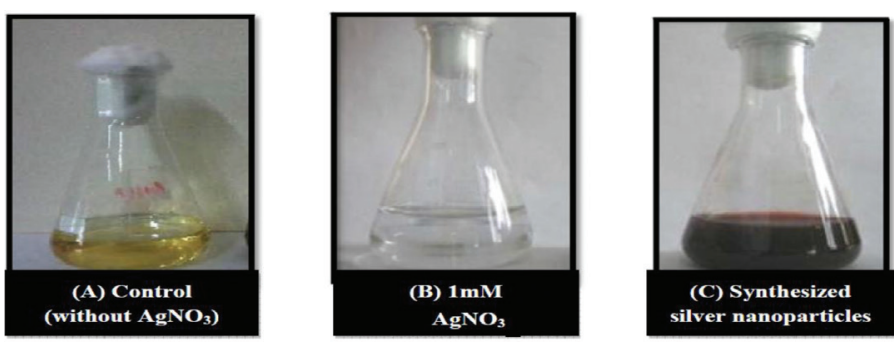

Figure 1: (A). Hydnocarpus pentandra leaves extract as the control; (B). $1 \mathrm{mM}$ silver nitrate solution; (C). Synthesized AgNPs.

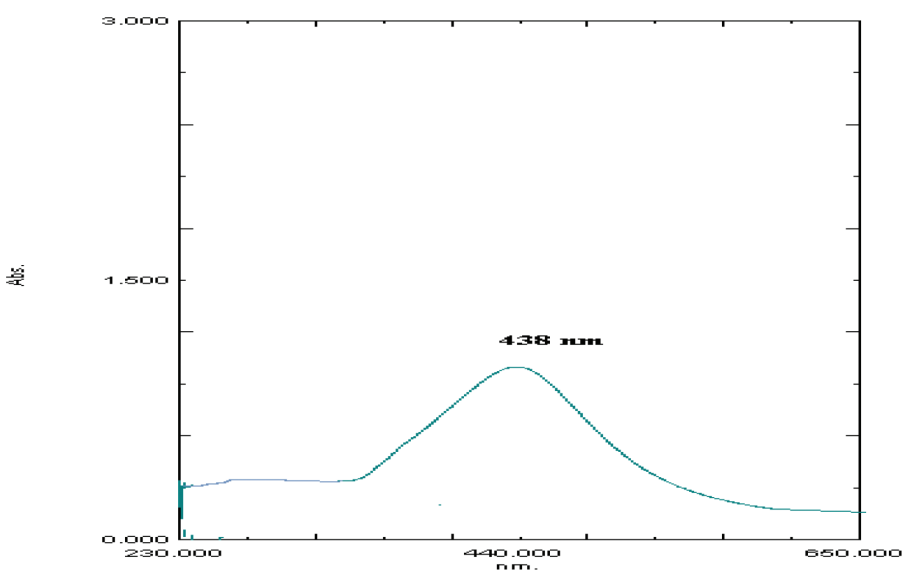

Figure 2: UV-Vis absorption spectrum of reduction of silver ions to silver nanoparticles Synthesized after $24 \mathrm{~h}$ reaction.

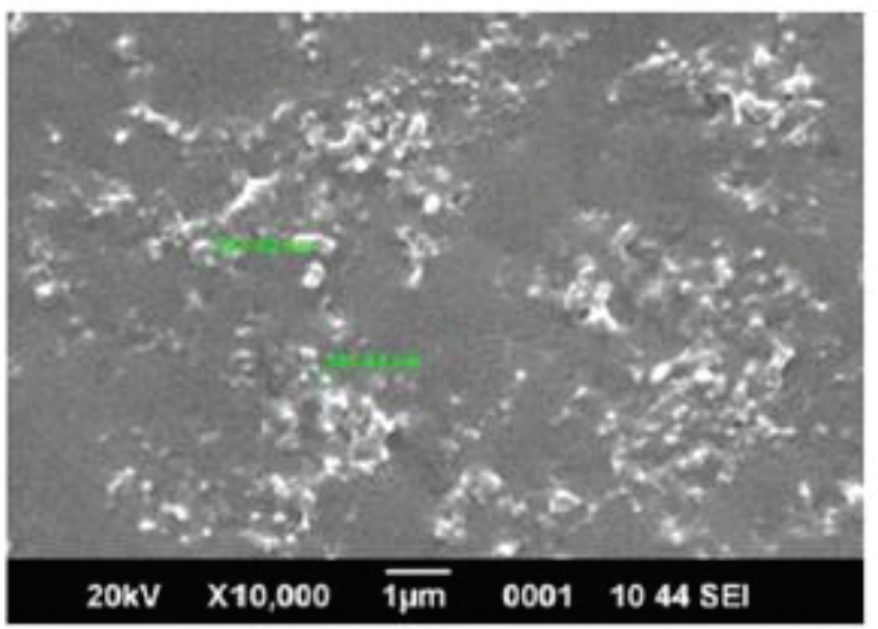

Figure 3: SEM analysis of silver nanoparticles synthesized from Hydnocarpus pentandra.

In addition, the toxicity of silver nanoparticles showed much higher than that of silver nitrate ( $25 \%$ dead cells) as shown in Table 1 .

\section{DISCUSSION}

The development of easy, reliable and eco-friendly method could help to increase research interest on synthesis of silver nanoparticles in the field of pharmaceutical sciences. Reduction of silver ions to silver nanoparticles during exposure to the plant extracts due to colour change. Silver

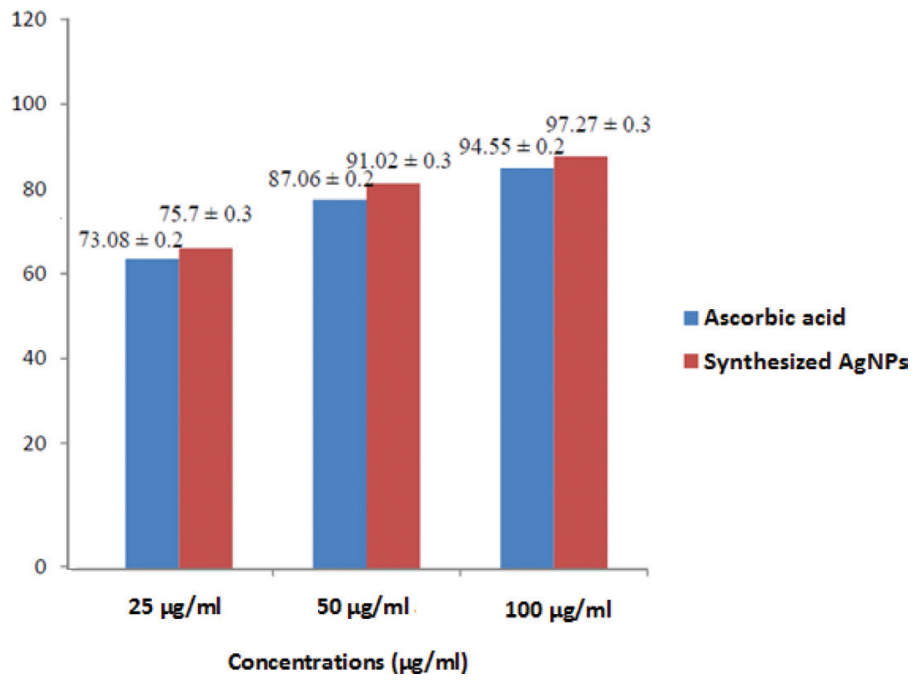

Figure 4: In vitro anti-oxidant activity by DPPH method.

\begin{tabular}{|c|c|c|}
\hline Cancer Cell Treatment & Dead (\%) & Viable (\%) \\
\hline Incubation Period & $24 \mathrm{~h}$ & $24 \mathrm{~h}$ \\
\hline MCF-7 and DMEM & $2.00 \pm 0.80$ & 98.00 \\
\hline MCF-7 and $1 \mathrm{mM}$ silver nitrate & $25.00 \pm 1.24$ & 75.00 \\
\hline MCF-7 and $10 \% \mathrm{H}$. pentandra Leaves & $36 \pm 2.30$ & 64.00 \\
\hline MCF-7 and $25 \mu \mathrm{g} / \mathrm{ml} \mathrm{AgNPs}$ & $58.00 \pm 1.80$ & 42 \\
\hline MCF-7 and $50 \mu \mathrm{g} / \mathrm{ml} \mathrm{AgNPs}$ & $75.00 \pm 3.24$ & 25 \\
\hline MCF-7 and $100 \mu \mathrm{g} / \mathrm{ml}$ AgNPs & $87.00 \pm 1.70$ & 13 \\
\hline
\end{tabular}

nanoparticles showed dark yellowish-brown colour in the aqueous solution due to the surface plasmon resonance phenomenon. ${ }^{8}$ The present study indicated that use of the plant extracts for the synthesis of silver nanoparticles with potent anti-cancer activity.

The silver nanoparticles were characterized by UV-Visible spectroscopy. Reduction of silver ions in the aqueous solution of silver nitrate during the reactions with active constituents present in the plant leaves extracts was observed by UV-Visible spectroscopy indicated that presence of silver nanoparticles in the solution was correlated with the spectra of UV-Visble. The plant leaves extract were mixed with the aqueous solution of silver ions, the colour of the solution was changed into dark yellowbrown colour due to surface plasmon resonance phenomenon and this indicated silver nanoparticles formation. The silver nanoparticles were formed with cubical uniform shape. The shape of the silver nanoparticles can change their electrical as well as optical properties. ${ }^{9}$ The SEM study indicated that relatively spherical shape of nanoparticles were formed with the diameter in the range of $141-202 \mathrm{~nm}$. Similar phenomenon was reported by Ponarulselvam et al 2012. ${ }^{10}$ Anti-oxidant activity can be evaluated by scavenging of the stable DPPH radical. This model is extensively used as it is less time consuming than the other methods. DPPH can accept an electron and hydrogen radical and can get converted into a stable diamagnetic molecule. DPPH contain an odd electron, and so it has a strong absorption at $517 \mathrm{~nm}$. When this electron becomes pairs off, the absorption decreases stoichiometrically with respect to the electron taken up. Such change in the absorbance produced in this reaction has been widely applied to assess the capacity of numerous molecules to act 
as free radical scavengers. ${ }^{11}$ Niramathi et al., showed that free radical scavenging activity of the AgNPs on DPPH radicals was found to increase with increase in the concentration. ${ }^{12}$ In present study, synthesized AgNPs have hydrogen donating ability or can scavenge free radicals. The antioxidant study of AgNPs showed the dose-dependent radical scavenging ability.

In this study, we have employed dose dependent approach to evaluate the toxicity of the green synthesized AgNPs on human breast cancer (MCF-7) cell line. The viability of MCF-7 cells considerably decreased with increasing the dosed of the AgNPs. The mortality data results obtained in the present study indicated to predict the potential of AgNPs not only because of the cyto-toxicity effects, but also relation of the potential for tumor reduction against MCF-7. The cyto-toxicity activity of AgNPs are the result of physicochemical interaction of silver ions with the functional groups of intracellular proteins of the cancer cells. ${ }^{13}$ However, more detailed study on mechanism of action of AgNPs need to be investigated with experimental proofs, the AgNPs seem to have considerable future.

\section{CONCLUSION}

It has been demonstrated that the leaves extracts of $H$. pentandra are capable of producing silver nanoparticles extracellularly and AgNPs are quite stable in solution. The biosynthesized AgNPs showed considerable antioxidant activity and excellent anti-cancer activity against breast cancer cells (MCF-7). The present study data indicated that green synthesized AgNPs could be considered alternative medicine for cancer therapy. However, further studies are needed to characterize the mechanism of action and toxicity of synthesized AgNPs involved with anti-cancer activity in an in vivo animal model.

\section{ACKNOWLEDGEMENT}

The authors thank the Kerala State council for science, technology and environment, Thiruvananthapuram, Kerala for the financial support.

\section{CONFLICT OF INTEREST}

The authors report no conflict of interest.

\section{ABBREVIATION USED}

H. pentandra: (Hydnocarpus Pentandra); AgNPs: (silver nanoparticles); MCF-7 cells: Michigan Cancer Foundation-7; (human breast adenocar- cinoma cell line); MTT: (3-(4,5-Dimethylthiazol-2-yl)-2,5-diphenyltetrazolium bromide); DPPH: (2,2-diphenyl-1-picrylhydrazyl).

\section{REFERENCES}

1. Jain D, Daima HK, Kachhwaha S, Kothari SL. Synthesis of plant-mediated silver nanoparticles using papaya fruit extract and evaluation of their anti-microbial activities. Dig J Nanomater Biostruct. 2009;4(3):557-63.

2. Satyavani K, Gurudeeban S, Ramanathan T, Balasubramanian T. Biomedical potential of silver nanoparticles synthesized from calli cells of Citrullus colocynthis (L.) Schrad. J Nanobiotechnol. 2011;9(1):43.

3. Kumar V, Yadav SK. Plant-mediated synthesis of silver and gold nanoparticles and their applications. J Chem Technol Biotechnol. 2009;84(2):151-7.

4. Shawkey AM, Rabeh MA, Abdulall AK, Abdellatif AO. Green nanotechnology: anticancer activity of silver nanoparticles using citrullus colocynthis aqueous extracts. Adv. in Life Sci.Technol. 2013;13:60-70.

5. Zargar M, Shameli K, Najafi GR, Farahani F. Plant mediated green biosynthesis of silver nanoparticles using Vitex negundo L. extract. J Ind Eng Chem. 2014;20(6):4169-75

6. Krishnaraj C, Jagan EG, Rajasekar S, Selvakumar P, Kalaichelvan PT, et al. Synthesis of silver nanoparticles using Acalypha indica leaf extracts and its antibacterial activity against water borne pathogens. Colloids and Surfaces B: Biointerfaces. 2010;76(1):50-6.

7. Elangovan K, Elumalai D, Anupriya S, Shenbhagaraman R, Kaleena PK, et al. Phyto mediated biogenic synthesis of silver nanoparticles using leaf extract of Andrographis echioides and its bio-efficacy on anticancer and antibacterial activities. J Photochem Photobiol B. 2015;151:118-24.

8. Vankar PS, Bajpai D. Preparation of gold nanoparticles from Mirabilis jalapa flowers. Indian J Biochem Biophys 2010;47:157-60.

9. Dubey M, Bhadauria S, Kushwah BS. Green synthesis of nanosilver particles from extract of Eucalyptus hybrida (safeda) leaf. Dig J Nanomater Biostruct. 2009;4(3):537-43.

10. Ponarulselvam S, Panneerselvam C, Murugan K, Aarthi N, Kalimuthu K, et al. Synthesis of silver nanoparticles using leaves of Catharanthus roseus Linn. G. Don and their antiplasmodial activities. Asian Pac J Trop Biomed. 2012;2(7):574-80.

11. Awika JM, Rooney LW, Wu X, Prior RL, Cisneros-Zevallos L. Screening methods to measure antioxidant activity of sorghum (Sorghum bicolor) and sorghum products. J Agric Food Chem. 2003;51(23):6657-62.

12. Niraimathi KL, Sudha V, Lavanya R, Brindha P. Biosynthesis of silver nanoparticles using Alternanthera sessilis (Linn.) extract and their antimicrobial, antioxidant activities. Colloids and Surfaces B: Biointerfaces. 2013 Feb 1;102:288-91.

13. Heydari R, Rashidipour M. Green synthesis of silver nanoparticles using extract of oak fruit hull (Jaft): synthesis and in vitro cytotoxic effect on MCF-7 cells. Int J Breast Cancer. 2015;2015:846743. 